\title{
Sindicalismo e Gênero no Brasil: a dinâmica recente
}

Sandro Pereira Silva ${ }^{l}$

André Gambier Campos ${ }^{2}$

Resumo: Este artigo encontra-se focado na discussão da participação de trabalhadores, do sexo masculino e feminino, nos sindicatos brasileiros. Sempre houve diferenças substanciais de participação entre ambos os gêneros. Os sindicatos, historicamente, mantiveram-se como espaços de acesso diferenciado para homens e mulheres, sendo que estas últimas sempre tiveram dificuldades para se aproximar da organização e se integrar à mobilização sindical. Porém, há evidências empíricas de que isso pode mudar em um futuro não muito remoto, pelo menos no que diz respeito à taxa de filiação sindical. De acordo com os números apresentados para as décadas de 1990 e 2000, homens e mulheres passaram a apresentar uma taxa de filiação mais parecida, indicando que ambos os gêneros se tornaram mais semelhantes em termos de proximidade aos sindicatos.

Palavras-chave: sindicalismo; igualdade de gênero; mercado de trabalho; filiação sindical; determinantes da participação feminina.

Abstract: This paper is focused on the discussion of the participation of workers, male and female, in the Brazilian unions. Where there were substantial differences in participation between both genders. Unions have historically remained as spaces of differential access for men and

\footnotetext{
${ }^{1}$ IPEA - Instituto de Pesquisa Econômica Aplicada

${ }^{2}$ IPEA - Instituto de Pesquisa Econômica Aplicada
} 
women, with the latter always had difficulty approaching the organization and integrating trade union mobilization. However, there is empirical evidence that this may change in the not too distant future, at least with regard to the rate of union membership. According to the numbers presented to the decades of 1990 and 2000, men and women began to show a most similar membership fee, indicating that both genders have become more similar in terms of proximity to the unions.

Keywords: trade unionism; gender equality; the labor market; union membership; determinants of female participation.

\section{Apresentação}

A temática do sindicalismo sempre se apresentou como um importante campo de estudo sobre o mundo do trabalho nas sociedades contemporâneas. Enquanto instrumento de mobilização e articulação dos trabalhadores, os sindicatos surgem praticamente junto com o próprio capitalismo, e, portanto, acompanha os processos de desenvolvimento da estrutura produtiva. À medida que economia se complexifica, as formas de organização dos sindicatos, suas possibilidades de atuação e suas contradições internas também se tornam mais complexas, abrindo novas oportunidades de investigação no intuito de entender melhor seus fenômenos recentes.

Este trabalho encontra-se focado na discussão da participação de trabalhadores, do sexo masculino e feminino, nos sindicatos 
brasileiros. Sempre houve diferenças substanciais de participação entre ambos os gêneros, mas há evidências empíricas de que isso pode mudar em um futuro não muito remoto. A discussão dessas evidências e possíveis alterações nas relações de gênero no universo do sindicalismo brasileiro é o objeto principal aqui proposto, que está organizado em outras quatro seções, excluindo esta apresentação.

A primeira seção deste artigo dedica-se a discutir a evolução do mercado de trabalho brasileiro nas duas últimas décadas, abrindo os indicadores por gênero. Na segunda seção, preocupou-se em recuperar o perfil do sindicalismo brasileiro nas décadas de 1990 e 2000 - sendo às vezes necessário retroceder mais no tempo, de modo a obter os traços mais definidores desse perfil. A terceira seção oferece evidências empíricas bastante inovadoras que dizem respeito à taxa de filiação sindical, verificando diferenças entre gênero e alguns fatores que determinam maior probabilidade de filiação das mulheres. Por fim, esforça-se em rever os aspectos mais importantes da discussão realizada ao longo desse artigo, levantando algumas questões sobre o futuro do sindicalismo no Brasil - especialmente, questões sobre as possibilidades abertas às mulheres, no sentido de se aproximarem ainda mais dos sindicatos nas próximas décadas. 


\section{Evolução recente do mercado de trabalho brasileiro}

Os estudos que compõem os campos da economia e da sociologia do trabalho envolvem diferentes dimensões de análise sobre os diversos fenômenos relativos ao mundo do trabalho. A questão da mobilização dos trabalhadores em organizações representativas, como no caso dos sindicatos, é uma dessas dimensões, pelo fato do sindicalismo ser historicamente a principal instituição de mobilização e luta por direitos e melhorias das condições de trabalho, sobretudo após o advento da Revolução Industrial e o desenvolvimento do capitalismo a nível global. Mas antes de entrar no sindicalismo propriamente dito, é preciso entender as principais características e dinâmicas do mercado de trabalho, para se obter uma visão geral da base social dos sindicatos.

No caso brasileiro, o mercado de trabalho tem apresentado nos últimos anos fortes variações, diretamente relacionadas com o ciclo econômico do país. $\mathrm{O}$ acelerado processo de desenvolvimento econômico pelo qual o país atravessou a partir dos anos 1950 e que se estendeu até o início dos anos 1980 resultou em fortes transformações estruturais na sociedade. A urbanização acompanhou o crescimento da economia, dada a demanda por mão de obra nos diversos setores industriais que se desenvolviam, além de diversos serviços que passaram a ser demandados nos grandes centros urbanos. Formou-se, nesse processo, uma massa de proletariados nas cidades que começaram a se organizar na luta por direitos sociais e trabalhistas. Paralelamente, o 
regime autoritário no país, sob o pretexto de manter a ordem nacional, repreendia fortemente as ações coletivas dos trabalhadores, que reclamavam entre outras coisas da política salarial imposta pelo governo. A volta da democracia nos anos 1980 proporcionou maior liberdade de atuação aos sindicatos, o que lhes conferiu um novo papel no desenho político nacional.

A partir dos anos 1990, uma série de fatores levou a um recrudescimento do processo de crescimento da estrutura produtiva nacional, com forte impacto na capacidade da economia em absorver mão de obra. Como resultado, o país se viu assolado pelo problema do desemprego e da informalização da mão de obra, gerando consequências sociais negativas, como o crescimento da pobreza e da desigualdade. Essa situação somente se reverteu quase uma década depois, na primeira metade dos anos 2000, quando a taxa de desemprego teve uma queda significativa, além de um aumento na formalização da mão de obra em praticamente todos os setores. Após um longo período de expansão durante a década de 1990, muito em função da queda nos postos de trabalho na indústria nessa época (SILVA; GONZALES, 2013), a informalidade caiu continuamente durante os anos 2000, atingindo 39,3\% em 2012, seu menor nível dos últimos 20 anos. Esse indicador tem uma grande importância para a análise da dinâmica sindical do país, visto que os sindicatos não abrigam trabalhadores informais, ou seja, quanto maior a formalização de um setor, mais ampla será a base de atuação sindical. 
Ao longo desse período, houve também variações significativas quando se diferencia a evolução dos indicadores por gênero, com uma tendência de diminuição das diferenças, embora os dados continuem sendo desfavoráveis às mulheres. A figura 1 mostra que a taxa de desemprego total no Brasil iniciou os anos $1990 \mathrm{em}$ um patamar de 7\%, cresceu até atingir a casa dos 10\% no final da década, manteve-se nos primeiros anos de 2000, até iniciar um período de queda acentuada a partir de 2004, terminando a série a uma taxa de $6,7 \%$ em 2012, a menor taxa da série. Ao avaliar por gênero, a mesma figura mostra que a tendência de variação foi basicamente a mesma para ambos os sexos, mas o desemprego feminino sempre esteve acima da média nacional. Nos períodos de mais alto desemprego, entre 1998 e 2004, observa-se um aumento do diferencial do desemprego entre homens e mulheres, mas após a recuperação do mercado de trabalho a diferença cai, fechando 2012 com 5,1\% para os homens e 8,9\% entre as mulheres.

Outro dado interessante a se observar é quanto à taxa de ocupação $^{3}$ da população economicamente ativa no mercado de trabalho brasileiro, mostrada na figura 2. Embora o percentual agregado tenha se mantido estável nesse período, entre os gêneros houve uma alteração importante. Enquanto entre os homens a taxa de ocupação veio caindo ao longo do tempo, de $75 \%$ para $68,2 \%$ no período, entre as mulheres

\footnotetext{
${ }^{3}$ A taxa de ocupação é definida como a razão entre o total de ocupados e a população em idade ativa (PIA).
} 
ocorreu o inverso, houve um aumento de $42,4 \%$ para $47,7 \%$ no mesmo período. Esses dados indicam a tendência de maior inserção das mulheres no mercado de trabalho nos últimos anos, o que incorre em questões políticas e sociológicas importantes de análise.

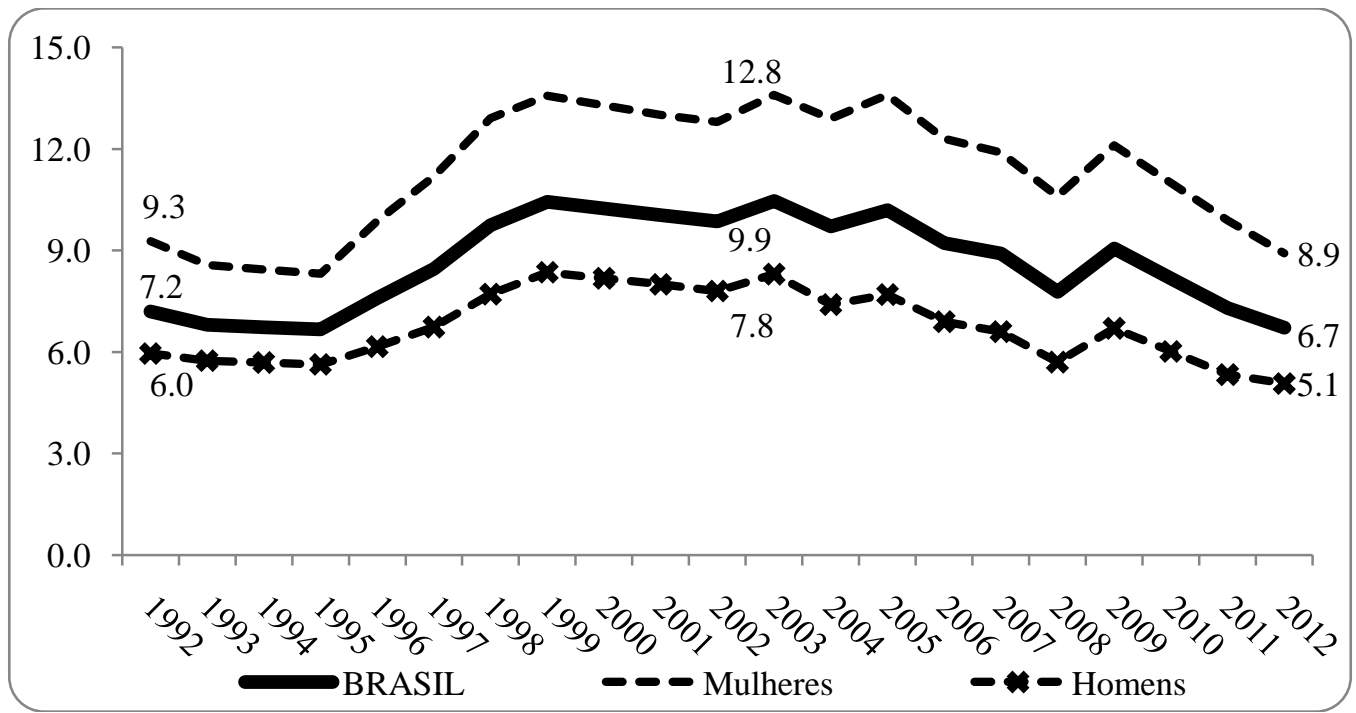

FIGURA 1 - EVOLUÇÃO DA TAXA DE DESEMPREGO NO BRASIL - 1992/2002 (EM \%)

FONTE: MICRODADOS PNAD/IBGE. ORGANIZADO POR IPEA (2013) 


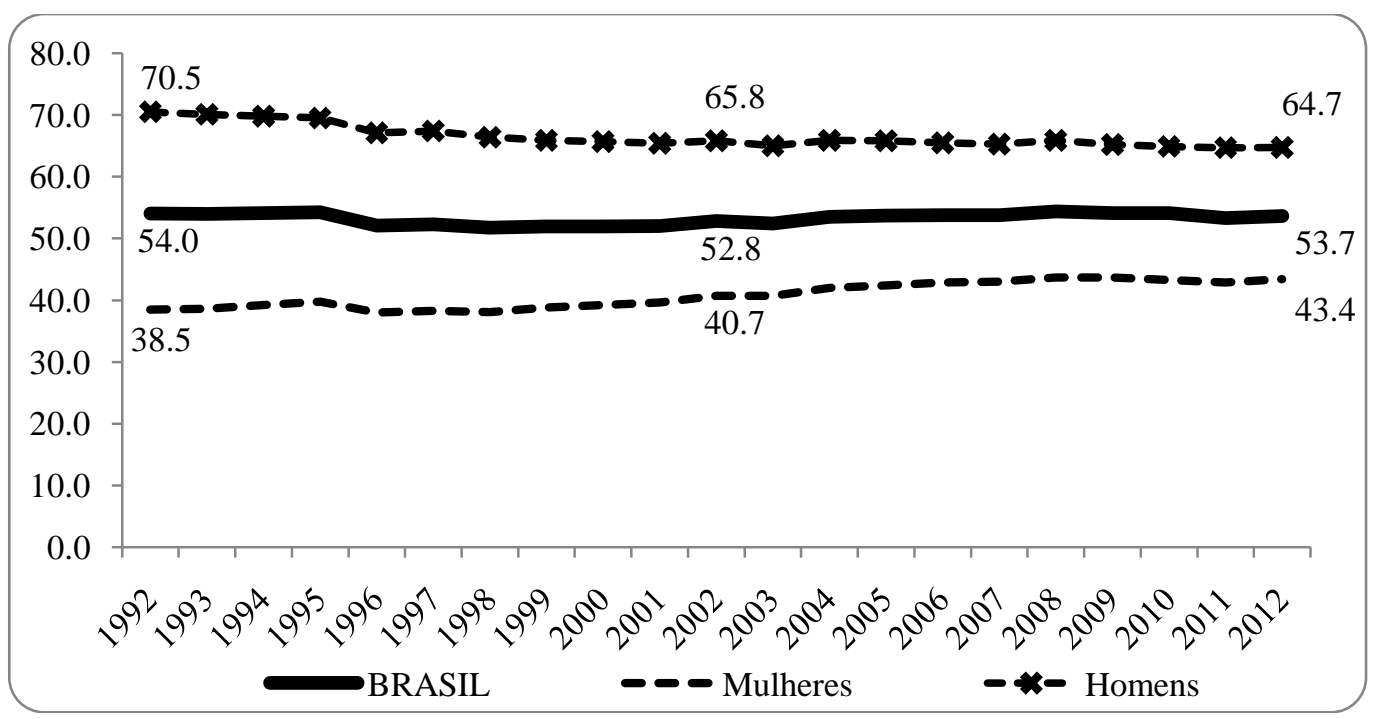

FIGURA 2 - EVOLUÇÃO DA TAXA DE OCUPAÇÃO NO BRASIL - 1992/2002 (EM \%)

FONTE: MICRODADOS PNAD/IBGE. ORGANIZADO POR IPEA (2013)

Ainda em termos de diferenças de gênero no mundo do trabalho, há uma série de trabalhos nos últimos anos que vem tentando abordar esse tema sob distintos ângulos de análise. Cada vez mais eles apontam para uma realidade "diversa, heterogênea e complexificada" (ANTUNES, 1995, p. 46).

Segundo Araújo (2005), um dos primeiros focos desses estudos refere-se à segmentação do mercado de trabalho, que tende a conferir historicamente às mulheres as posições desprestigiadas, mais instáveis e desprotegidas. Posteriormente foram se ampliando no intuito de envolver as continuidades e descontinuidades na inserção da mulher no mercado de trabalho. Nesse grupo estão estudos sobre as diversas formas de inserção do trabalho feminino, tais como o trabalho 
doméstico e as relações entre o trabalho produtivo e o trabalho reprodutivo. Outro foco importante refere-se às diferenças nos padrões salariais e nos vínculos empregatícios, com base em uma série de características pessoais, tais como: cor de pele, escolaridade, qualificação, entre outras. Assim, afirmou a autora que:

[...] o estudo das mudanças recentes no mundo do trabalho a partir de uma perspectiva de gênero permitiu dar visibilidade às formas e aos lugares da inserção crescente das mulheres no trabalho extradoméstico. De um lado, observou-se o maior acesso das mulheres a postos antes ocupados apenas por homens, a postos de liderança e gerenciamento, bem como a definição de habilidades consideradas femininas como competências centrais associadas ao trabalho flexível, que tornaram preferencial o recrutamento de mulheres para cargos específicos nos bancos e em distintos pontos do processo produtivo. De outro, as formas atípicas de contrato, a crescente informalidade, a precarização e a deteriorização das condições de trabalho incidem de forma especial e mais aguda sobre as trabalhadoras [...] (p. 94).

Hirata (2007) também ressaltou o fato da inserção feminina no mercado de trabalho ser marcada por uma lógica de precariedade. De maneira geral, as mulheres se inserem em postos de trabalho de menor qualificação, salários mais baixos, e sofrem impactos diferenciados no tocante a mudanças e inovações no processo produtivo. Além disso, recai sobre elas o fardo da dupla jornada de trabalho, uma vez que 
continuam sendo as responsáveis pela maioria das atividades domésticas e de cuidados familiares.

Portanto, são múltiplas as situações que caracterizam as relações de trabalho e remuneração desiguais entre homens e mulheres, o que impossibilita definir um único padrão de desigualdade (GUIMARÃES, 2002). Por outro lado, a inserção feminina no mercado de trabalho e todas as consequências sociológicas que lhe são derivadas permitiram também o crescimento da atuação das mulheres em espaços reivindicativos e movimentos sociais, inclusive nos sindicatos, que são as principais instituições de representação e mobilização da classe trabalhadora. Esses espaços coletivos de atuação são importantes na medida em que permitem o reconhecimento e o compartilhamento de experiências, práticas e demandas comuns, que auxiliam as mulheres na reflexão acerca de suas experiências (LEMOS, 2011).

\section{Características gerais do sindicalismo no Brasil}

Com base nas informações da seção anterior, percebe-se que o mercado de trabalho no Brasil foi marcado nos últimos anos por grandes flutuações relacionados diretamente ao desempenho da economia, com destaque para a recuperação dos principais indicadores referentes a emprego e formalização na década anterior. Os números apresentados também explicitaram o contínuo aumento da participação feminina no mercado de trabalho, mas ainda em condições 
desfavoráveis com relação à qualidade no emprego em comparação com os homens, apesar dos diferenciais terem diminuído nos últimos anos. A visão geral desses indicadores auxilia na análise do comportamento do sindicalismo no Brasil contemporâneo, já que o comportamento do determina a expansão ou retração da base social sobre a qual atuam os sindicatos, além de implicar nas estratégias de atuação e negociação em cada setor.

Muito em função desse comportamento, o Brasil passou nos últimos anos do século $\mathrm{XX}$ um período de ascensão e crise do sindicalismo, enquanto movimento social e político. Segundo Alves (2000), o ano de 1978 marcou um cenário de organização e unidade da luta da classe trabalhadora, sendo um marco histórico para o ressurgimento do movimento sindical no país. O ponto de partida para esse movimento é a insurgência dos trabalhadores do complexo industrial do chamado $\mathrm{ABC}$ paulista contra o arrocho salarial que caracterizava a lógica de acumulação capitalista no país à época. Esse movimento foi tão importante que passou a ser considerado na literatura como um "novo sindicalismo", que passou a se desenvolver "a partir de um mundo do trabalho estruturado, resultado da expansão capitalista dos anos 1960 e 1970".

Os resultados desse processo transpassaram a esfera econômica, com impacto significativo também no debate político do país (ABRAMO, 1986; MENEGUELLO, 1989; RODRIGUES, 1990). Toda essa capacidade mobilizadora se manteve ao longo da década de 
1980. As ações organizadas pelos sindicatos, em especial as greves, se destacaram pelo elevado número de trabalhadores envolvidos, mantendo-se, muitas delas, por longos períodos de tempo (NORONHA, 1994; SANDOVAL, 1994). Entre suas consequências está a criação da Central Única dos Trabalhadores (CUT), em 1983, além de participar ativamente do "Movimento Diretas Já" que exigia o fim do regime militar e o retorno da democracia no país.

No entanto, essa "explosão do sindicalismo" iniciado no fim dos anos 1970 teve seu ponto de inflexão já a partir do início dos anos 1990. Isso devido ao cenário de reestruturação produtiva que marcou a economia brasileira nesse período e sua nova inserção dependente no capitalismo global, afetando diretamente as bases do trabalho organizado do setor industrial e dos serviços. A destruição de milhares de postos de trabalho formais, aliado à incapacidade de geração de novas oportunidades de inserção produtiva, tiveram como resultado um aumento do desemprego ao longo da década, como visto anteriormente, além da diminuição da remuneração do trabalho (CACCIAMALI, 2000). Consequentemente, houve também um enfraquecimento da capacidade de organização e mobilização dos sindicatos, uma vez que uma grande massa de trabalhadores deixou de pertencer às bases dos sindicatos. Entre esses grupos estava uma parte significativa de trabalhadores setor industrial, justamente aqueles reconhecidos como os mais organizados (CARDOSO, 2003). 
Sob esse novo cenário, as grandes organizações sindicais passaram a rever suas estratégias de mobilização, o que gerou uma atuação menos combativa e mais defensiva, negociadora, caracterizado por alguns autores como um período de "sindicalismo de resultados" (ANTUNES, 1995), "cooperação conflitiva" (RODRIGUES, 1995), ou "convergência antagônica" (OLIVEIRA, 1993). De acordo com Alves (2000, p. 113), isso é explicado pelo fato do sindicalismo no Brasil ainda apresentar uma estrutura sindical frágil no plano organizativo, cujas principais características são: $i$ ) ela é descentrada, fragmentada e dispersa por uma miríade de sindicatos municipais, em sua maioria pouco expressivos e com exígua capacidade de barganha; ii) é descentralizada, com parcas iniciativas e formas de ação unificadas (apesar da constituição das centrais sindicais a partir de 1983); iii) é desenraizada, em virtude de não ter inserção nos locais de trabalho, sendo uma estrutura externa às empresas; e $i v$ ) é verticalizada, com imensas dificuldades de articular, numa perspectiva horizontal mais ampla, a organização da classe, permanecendo vinculada à categoria assalariada. Todavia, o autor ressaltou que, mesmo que os sindicatos não tenham demonstrado a mesma vitalidade política das décadas anteriores, o índice de greves permaneceu significativo nos anos 1990.

Na primeira década dos anos 2000, novos elementos surgem para o debate em torno da questão sindical no Brasil. O mercado de trabalho se recuperou ao longo dos anos, sobretudo a partir de 2004, e atingiu níveis de desemprego bem abaixo daqueles da década passada, 
além de maiores taxas de formalização da mão de obra. O que esse novo cenário impactou no sindicalismo?

Para Campos (2014), em que pese o momento favorável da economia, a associação dos trabalhadores aos sindicatos não avançou, ou pelo menos não como poderia ter avançado. Isto é, o crescimento do emprego, que ampliou as bases dos sindicatos, não foi acompanhado proporcionalmente pelo aumento da filiação sindical no período. Por isso, o autor percebeu que os anos 2000 registraram um descolamento entre a dinâmica laboral e a sindical. Embora as bases dos sindicatos tenham se ampliado significativamente nos anos 2000, alguns setores apresentaram queda em sua densidade sindical, ou seja, a taxa de associação ou filiação aos sindicatos. Nesses setores estão inclusos segmentos que contavam com algumas das taxas de sindicalização mais elevadas em 2001, tais como: extração de petróleo e gás; materiais e equipamentos de transporte; máquinas e equipamentos industriais; e materiais siderúrgicos e metalúrgicos. Por outro lado, alguns segmentos tiveram adensamento em suas bases sindicais, com destaque para: materiais e equipamentos diversos; alimentos, bebidas e fumo; materiais jornalísticos, editoriais e gráficos. Uma observação importante nesse caso é que os segmentos em que os sindicatos conseguiram adensar suas bases mostraram-se bastante minoritários na indústria. Dessa forma, Campos (2014) entendeu que a fragilidade dos sindicatos, própria dos anos 1990, não pareceu inteiramente "superada" nos 2000. 
No entanto, o fato de haver esse descolamento, por si só, não caracterizaria uma crise do sindicalismo nos anos 2000. Esse é o ponto de vista de Cardoso (2014), ao argumentar que o movimento sindical brasileiro pode ser considerado atuante por diversos aspectos, sobretudo no que tange aos resultados das negociações coletivas, as taxas de greve e a presença de sindicalistas nas esferas de representação política. Sob essa perspectiva, o autor discutiu os principais pontos encontrados na literatura referentes às "dimensões da crise" do sindicalismo. Uma delas diz respeito à expressiva queda das taxas de sindicalização do total da população assalariada adulta no país, que caiu de $22,5 \%$ no início dos anos 1990 para 18,1\% em 2012. Essa queda é vista como indicador de menor proximidade dos trabalhadores com as organizações sindicais que os representam compulsoriamente. Porém, o autor ressaltou que, ainda assim, são cerca de 16 milhões de trabalhadores filiados mesmo apesar da queda nos últimos anos, o que não deixa de ser um número bastante expressivo, se comparado com outros países.

Outra dimensão analisada por Cardoso (2014) diz respeito à perda de capacidade do sindicalismo para a ação coletiva, com números para mostrar que tal afirmativa recorrente na literatura está equivocada. De acordo com os dados apresentados, no ano de 2012 ocorreram perto de 900 greves em todo o país, sendo o maior volume de greves desde 1997. Além do mais, em $75 \%$ delas os trabalhadores conseguiram ser atendidos totalmente ou em parte de suas reivindicações, e $95 \%$ das categorias negociaram reajustes salariais acima da inflação, um recorde 
histórico segundo Cardoso. Tais fatores demonstram um significativo sucesso na ação coletiva recente dos trabalhadores. Esse resultado foi bem diverso do que ocorreu nos anos 1990, quando as negociações eram majoritariamente desfavoráveis aos trabalhadores, devido ao grau de fragilidade dos sindicatos diante da situação desfavorável da economia e, por conseguinte, do mercado de trabalho brasileiro ${ }^{4}$.

Pichler (2011), ao analisar as dinâmicas recentes de afiliação sindical entre todos os trabalhadores brasileiros (inclusive rurais), observou que houve queda na densidade sindical nos 1990, mas que nos anos 2000 houve uma recuperação desse indicador. Porém, ele diagnosticou também diferenças importantes quanto à relação de gênero. Durante a "fase de declínio" do sindicalismo (anos 1990), houve forte queda na taxa de sindicalização entre os homens, porém, entre as mulheres ela aumentou. Ou seja, a queda na densidade sindical nos anos 1990 deve-se exclusivamente à queda da filiação masculina. Já no "período de recuperação" (anos 2000), tanto entre os homens quanto entre as mulheres observou-se elevação da taxa sindical. Mesmo assim, o aumento da densidade sindical entre as mulheres foi mais elevado do que entre os homens, o que demonstra a manutenção da tendência vinda da década passada de maior filiação relativa entre as mulheres, embora

\footnotetext{
${ }^{4}$ Desemprego em alta, ameaça de migração por parte das empresas, reestruturação produtiva, flexibilização dos contratos, crescimento da informalidade, desindustrialização dos empregos, tudo isso reduziu, e muito, o poder de barganha dos sindicatos, que, ademais, perderam base de sustentação em razão da redução dos empregos formais (CARDOSO, 2014).
} 
o total de filiados masculinos continue sendo superior. Em termos regionais, as mulheres obtiveram aumento da taxa de sindicalização em todas as regiões brasileiras, com destaque para o Nordeste e para as áreas rurais. Outro ponto destacado por Pichler (2011, p. 39) é que a "crise financeira internacional de 2009 afetou mais fortemente a afiliação masculina do que a feminina".

Para além da evolução recente do sindicalismo em números agregados, é importante também discutir alguns fatores gerais, inerentes a sua própria natureza institucional, que determinam ou diferenciam a inserção de homens e mulheres em organizações sindicais. Araújo (2005) é uma das autoras que abordaram a temática do sindicalismo como um campo importante para estudos sobre as relações de gênero no mundo do trabalho. Os sindicatos são conhecidos historicamente como espaços de domínio masculino, que tende a excluir ou "invisibilizar" a presença feminina em suas formas específicas de organização. Porém, lembrou a autora que as mulheres tiverem uma participação importante desde o surgimento do "novo sindicalismo" no Brasil, levantando o debate sobre a necessidade de se ações dirigidas à classe trabalhadora que não levassem em conta apenas relações produtivas, mas também as reprodutivas. Um marco histórico desse movimento foi a realização do $1^{\circ}$ Congresso das Operárias da Metalurgia de São Bernardo do Campo, em janeiro de 1978, em pleno ABC paulista. Outros eventos importantes foram ocorrendo posteriormente, como a criação da Comissão Nacional sobre a Mulher Trabalhadora (CNMT), da CUT, em 
1986, além de comissões de mulheres em diversos sindicatos filiados (BERTOLIN; KAMADA, 2012). Aos poucos, o sindicalismo passou a incluir em suas pautas temas diretamente ligados aos interesses das mulheres em sua relação com o mundo do trabalho, incluindo a proteção aos direitos da maternidade, luta contra o assédio social, igualdade de oportunidades, entre outros.

Todavia, alguns autores apontaram que a participação das mulheres nas estruturas de poder nos sindicatos encontra-se, de modo geral, diretamente vinculada à manutenção de uma hierarquia social e técnica com a supremacia masculina (HIRATA, 1998). Um fato que exemplifica tal afirmação é a baixa participação de mulheres em cargos de diretoria dos sindicatos. Carvalhal (2001, p. 9) diagnosticou em sua pesquisa que poucas organizações sindicais possuem 30\% dos cargos de sua diretoria ocupados por mulheres, inclusive em segmentos cuja base é equilibrada em termos de empregos femininos e masculinos, ou mesmo com maioria feminina. A própria CUT, central que elaborou essa proposta, não observa essa condição em seus afiliados. Dessa forma, a autora concluiu que, assim como entre as mulheres são observados maior incidência de cargos de menor qualidade no mercado de trabalho (informais, tempo parcial, de menor rendimento, etc.), nos sindicatos a mulher trabalha "no espaço imposto pela maioria masculina, nos cargos que não impõe decisões, sendo cargos secundários [...], não atuante no processo de tomada de decisões 
sindicais". E por falar em centrais sindicais, em 2009 apenas 21,2\% dos cargos em suas diretorias era composto por mulheres.

\section{Evidências Empíricas}

\section{Taxa de filiação}

Nesta subseção, analisa-se a taxa de filiação aos sindicatos, estritamente sob a ótica relativa (proporção dos trabalhadores que decidem se sindicalizar) ${ }^{5}$. Leva-se em conta apenas os trabalhadores dos seguintes grupos: entre 16 e 65 anos de idade, assalariados e registrados, celetistas e estatutários, situados no Brasil urbano ${ }^{6}$. Isso porque, ao se tratar de filiação sindical, é costume referir-se ao trabalho em 'idade ativa' (de 16 a 65 anos), 'subordinado' (assalariado) e reconhecido pela regulação laboral (registrado perante o Estado). Ademais, é comum na literatura a referir-se somente ao trabalho vinculado a sindicatos urbanos para análises desse tipo (RODRIGUES, 1979, 1989, 1990; VIANNA, 1976).

\footnotetext{
5 A respeito das controvérsias em torno da taxa de filiação, questionando se ela realmente consiste em indicador de força da organização e da atuação dos sindicatos, ver Cardoso (1999; 2003); Rodrigues (1979).

${ }^{6}$ Os trabalhadores celetistas são assalariados regulados pela Consolidação das Leis do Trabalho (Decreto Lei $n^{\circ}$ 5.452/1943). Já os trabalhadores estatutários são assalariados regidos por estatutos específicos, tal como a Lei $\mathrm{n}^{\circ}$ 8.112/1990 (estatuto dos trabalhadores civis federais).
} 
Ao longo das últimas décadas, a taxa de filiação sindical diminuiu sensivelmente no país. Entre 1992 e 2002, passou de 32,4\% do total de trabalhadores para 29,4\%. Entre 2002 e 2012, ela diminuiu ainda mais significativamente, de $29,4 \%$ para $23,7 \%$ desse total, como demonstra a figura 3. As razões desse comportamento da filiação aos sindicatos já foram estudadas pela literatura (CARDOSO, 2003, 2013). Na década de 1990, elas estiveram associadas à fraqueza da economia brasileira, que fez com que as bases sindicais reduzissem seu tamanho (em sentido absoluto) e, ao mesmo tempo, se rarefizessem (em sentido relativo). Na década de 2000, tais bases até chegaram a ampliar seu tamanho (em perspectiva absoluta), mas não conseguiram se adensar (em perspectiva relativa) - essencialmente, porque a filiação aos sindicatos não acompanhou o avanço da ocupação dos trabalhadores (CAMPOS, 2013). 


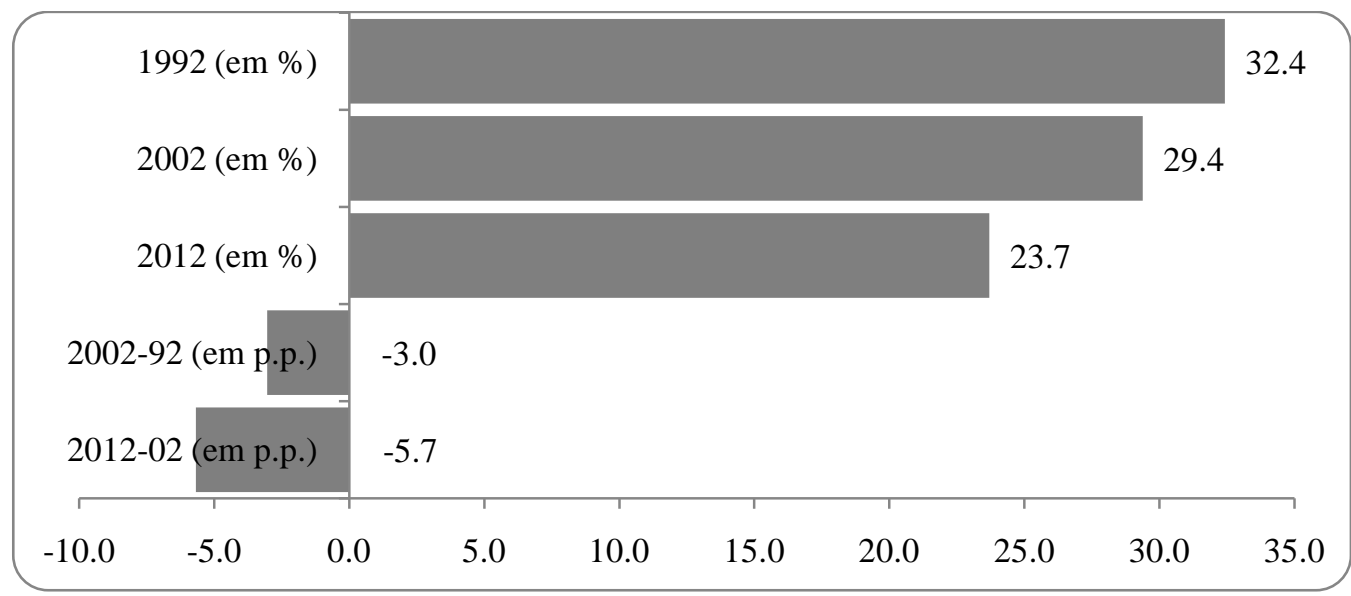

FIGURA 3 - FiLIAÇÃo (E VARIAÇão DA FILIAÇÃo) DE TRABALHADORES AOS SINDICATOS, NOS ANOS DE 1992, 2002 E 2012 (EM \% E EM P.P.)

FONTE: MICRODADOS PNAD/IBGE. ELABORAÇÃO DOS AUTORES.

Nota: Trabalhadores de 16-65 anos, assalariados registrados, celetistas e estatutários, no Brasil urbano.

Seja como for, comparando homens e mulheres, é possível observar comportamentos distintos no que se refere à filiação aos sindicatos. Historicamente, a taxa masculina se mostrou superior à feminina - o que, em alguma medida, consistiu em um reflexo da inserção mais precária das mulheres no mercado laboral (GUIMARÃES, 2002). Não obstante, entre 1992 e 2002, a taxa masculina reduziu-se mais que a feminina ( $-4,0$ p.p. contra $-1,2$ p.p.). Além disso, entre 2002 e 2012, esse fenômeno voltou a ocorrer, ainda que de forma um pouco menos pronunciada (-5,9 p.p. contra $-5,3$ p.p.), 
como demonstra a figura 5. Como resultado, a diferença que havia entre a filiação de homens e mulheres a sindicatos, que chegava a 1,14 vez no ano de 1992, diminuiu para somente 1,03 no de 2012 (tabela 1 e figuras 4 e 5). Em termos de taxas, ambos os gêneros têm agora grau bastante semelhante de proximidade com a organização sindical - o que, historicamente, parece ser uma novidade importante.

TABELA 1. FiLIAÇÃo DE TRABALHADORES AOS SINDICATOS, POR SEXO, NOS ANOS DE 1992, 2002 E 2012 (EM \%)

\begin{tabular}{|l|c|c|c|}
\hline Taxas (em \%) & $\mathbf{1 9 9 2}$ & $\mathbf{2 0 0 2}$ & $\mathbf{2 0 1 2}$ \\
\hline Masc. & 33,9 & 29,9 & 24,0 \\
\hline Fem. & 29,8 & 28,6 & 23,3 \\
\hline & & & \\
\hline Comparação entre taxas (em vezes) & 1992 & 2002 & 2012 \\
\hline Homens / Mulheres & 1,14 & 1,05 & 1,03 \\
\hline
\end{tabular}

Fonte: Microdados PNAD/IBGE. Elaboração dos autores.

Nota: Trabalhadores de 16-65 anos, assalariados registrados, celetistas e estatutários, no Brasil urbano.
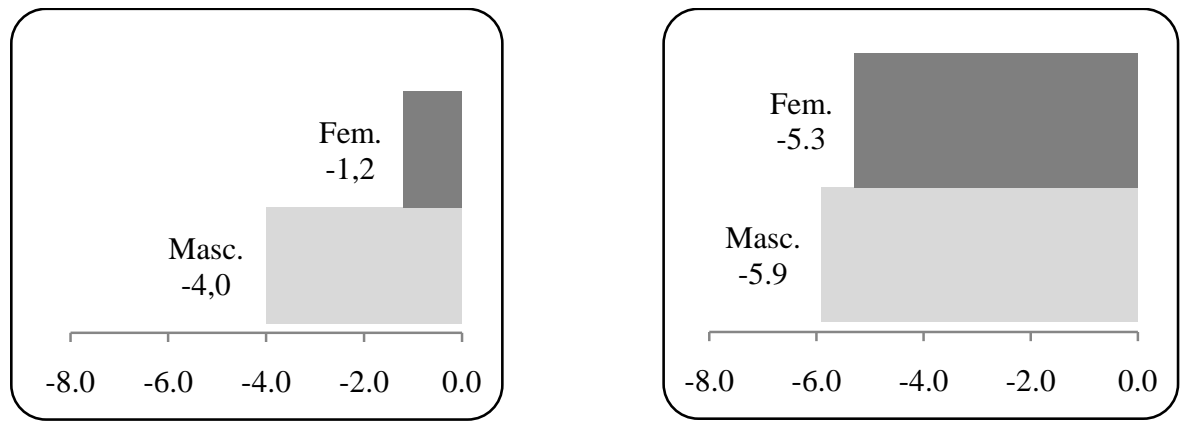

FIGURA 4 - VARIAÇõES DA FILIAÇÃo DE TRABALHADORES AOS SINDICATOS, POR SEXO, ENTRE OS ANOS DE 1992, 2002 E 2012 (EM P.P.)

FONTE: MICRODADOS PNAD/IBGE. ELABORAÇÃO DOS AUTORES.

Nota: Trabalhadores de 16-65 anos, assalariados registrados, celetistas e estatutários, no Brasil urbano. 


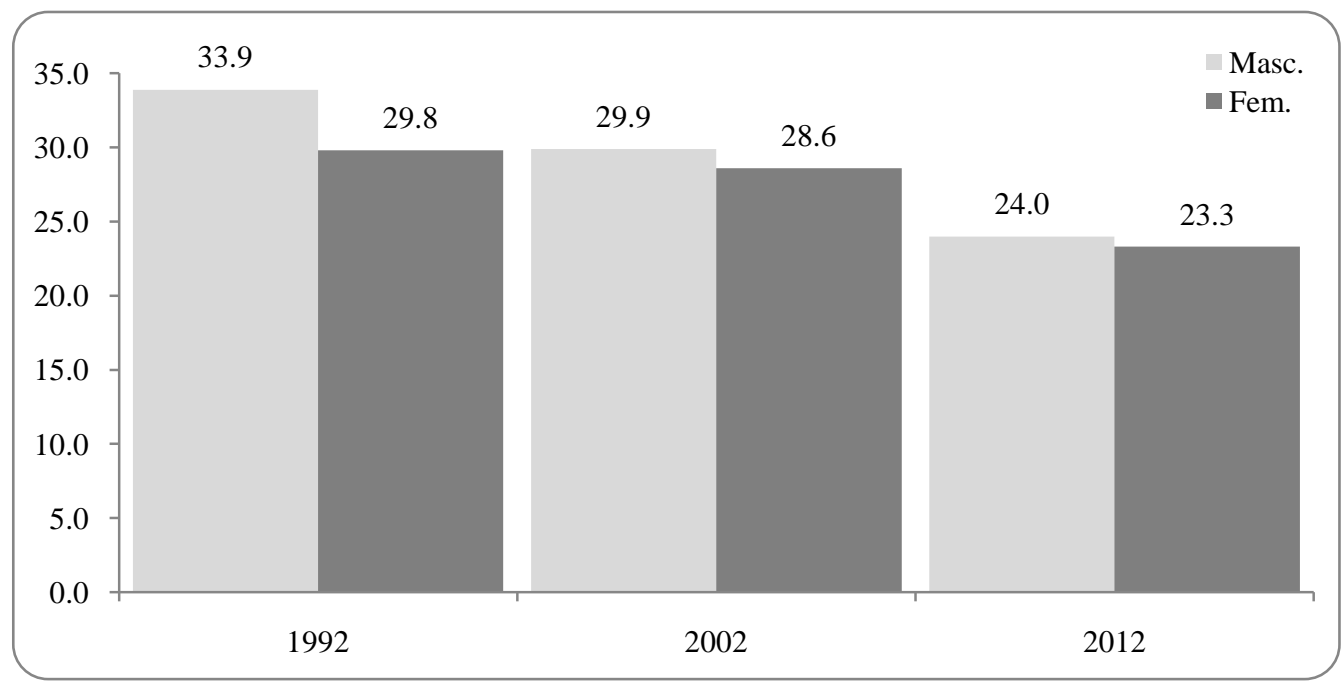

FIGURA 5 - FILIAÇÃo DE TRABALHADORES AOS SINDICATOS, POR SEXO, NOS ANOS DE 1992, 2002 E 2012 (EM \%)

FONTE: MICRODADOS PNAD/IBGE. ELABORAÇÃO DOS AUTORES.

Nota: Trabalhadores de 16-65 anos, assalariados registrados, celetistas e estatutários, no Brasil urbano.

Essa novidade pode ser constatada também ao analisar as taxas de filiação de homens e mulheres, por regiões do país e por setores econômicos.

No que diz respeito às regiões, em quase todas elas, as diferenças entre as taxas masculinas e femininas se reduziram no intervalo entre 1992 e 2012 (ainda que isso nem sempre tenha ocorrido de modo linear). Apenas como exemplo, no Nordeste, tais diferenças eram de 7,3 p.p. a favor dos homens em 1992 e caíram para 2,4 p.p. a favor das mulheres em 2012 (figura 6). 
No que concerne aos setores, em todos eles, essas diferenças diminuíram no lapso entre 1992 e 2012 (ainda que nem sempre de maneira linear). Como exemplo, na indústria de transformação, tais diferenças eram de 8,4 p.p. a favor dos homens em 1992 e caíram para 4,1 p.p. em 2012. Já nos serviços, esses valores corresponderam, respectivamente, a 7,0 p.p. e 1,2 p.p. (figura 7).

Em suma, seja por regiões do país, seja por setores econômicos, observa-se que as taxas de filiação masculinas e femininas se aproximaram significativamente. $\mathrm{O}$ que, em certa medida, indica que ambos os gêneros têm hoje grau semelhante de proximidade com a organização sindical.

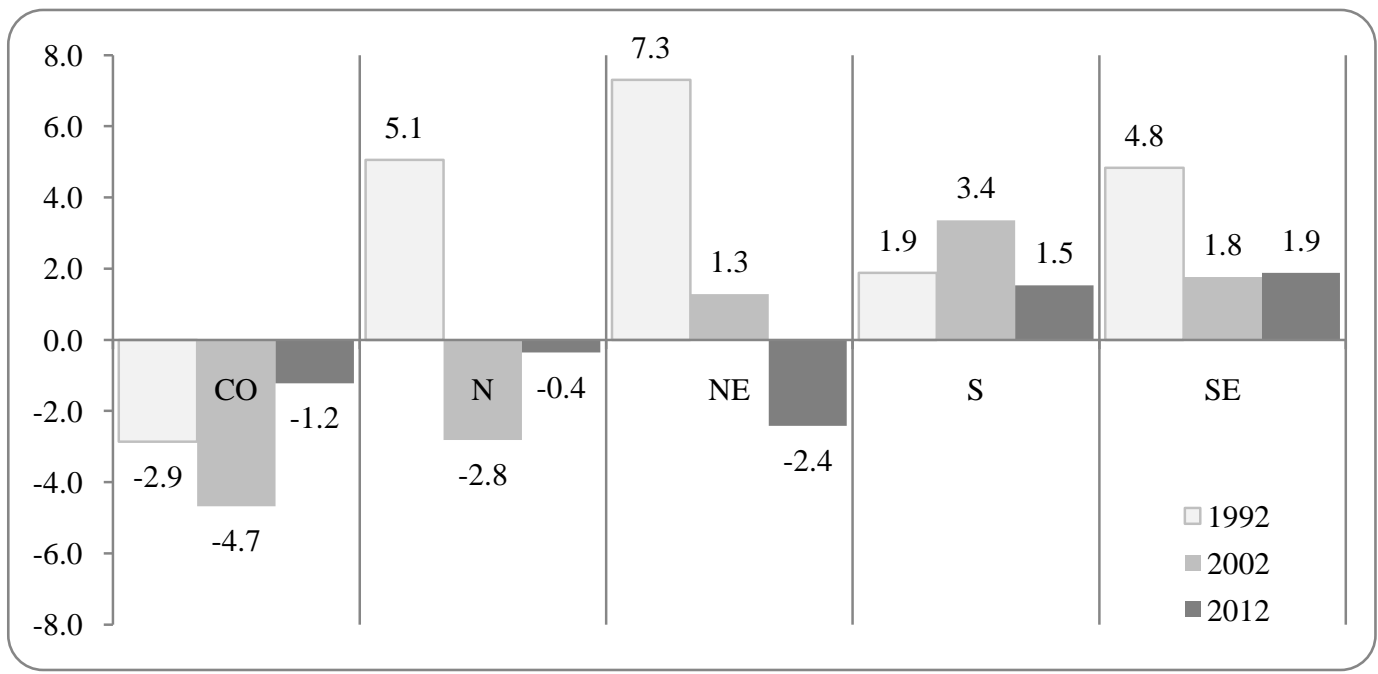

FIGURA 6 - DIFERENÇAS DE FILIAÇÃO DE TRABALHADORES (MASC. - FEM.) AOS SINDICATOS,

POR REGIÃO, NOS ANOS DE 1992, 2002 E 2012 (EM P.P.)

FONTE: MiCRODADOS PNAD/IBGE. ElABORAÇÃO DOS AUTORES.

Nota: Trabalhadores de 16-65 anos, assalariados registrados, celetistas e estatutários, no Brasil urbano. 


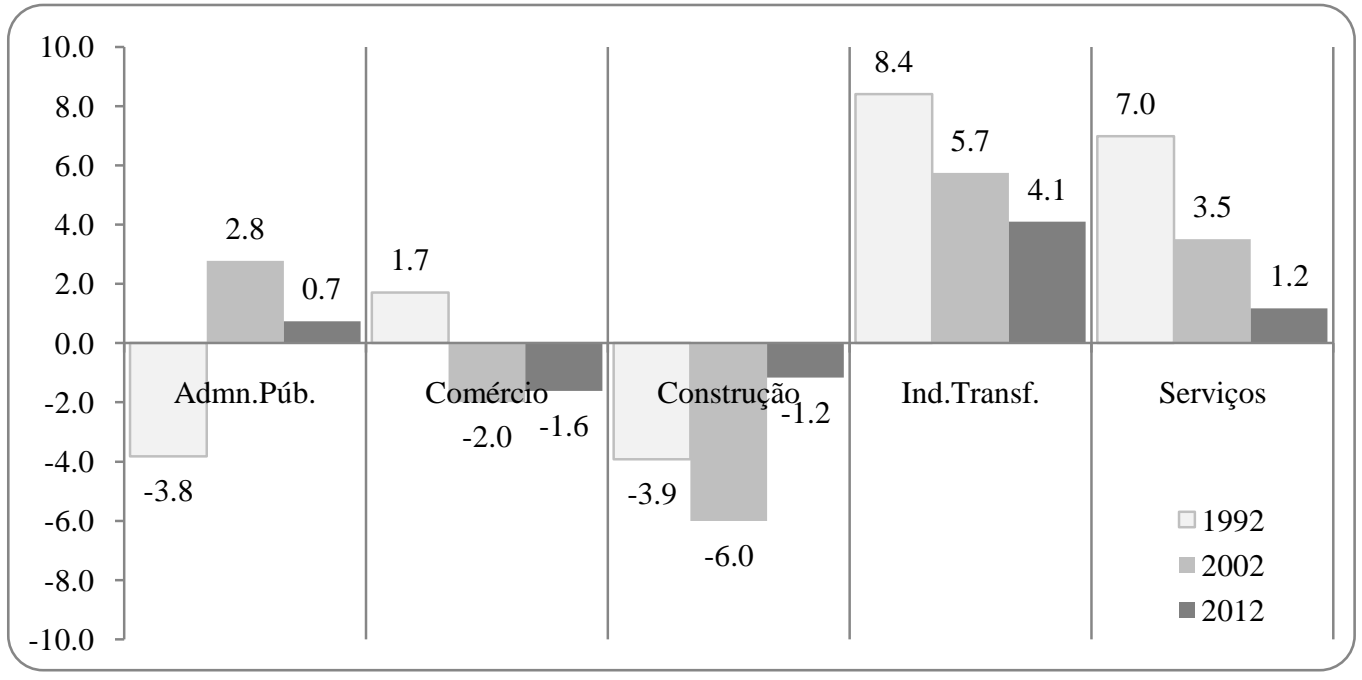

FIGURA 7 - DIFERENÇAS DE FILIAÇÃO DE TRABALHADORES (MASC. - FEM.) AOS SINDICATOS, POR SETOR, NOS ANOS DE 1992, 2002 E 2012 (EM P.P.)

FONTE: MICRODADOS PNAD/IBGE. ELABORAÇÃO DOS AUTORES.

Nota: Trabalhadores de 16-65 anos, assalariados registrados, celetistas e estatutários, no Brasil urbano.

\section{Perfil da filiação}

Na subseção anterior, a ideia foi analisar a taxa de filiação aos sindicatos, comparando homens e mulheres. Já nesta, o intuito será estudar o perfil dessa filiação, pois a organização e a mobilização sindical não se apoiam sobre os trabalhadores considerados em abstrato. 
Pelo contrário, se apoiam sobre perfis específicos, que apresentam maior proximidade com essa organização/mobilização ${ }^{1}$.

Dadas as limitações da fonte de informações usada neste artigo (a Pnad/IBGE), a ideia é analisar o perfil da filiação a sindicatos por meio dos seguintes atributos, assim categorizados: i) Atributos demográficos: cor (negra ou branca) ${ }^{2}$; condição na família (pessoa de referência ou outra condição qualquer); se estuda (não ou sim); anos de estudo (até 11 anos ou 12 anos ou mais); área de residência (não metropolitana ou metropolitana); se é migrante (não ou sim); e ii) Atributos ocupacionais: porte do estabelecimento de trabalho (até 10 ocupados ou 11 ou mais ocupados); jornada semanal (até 40 horas ou 41 horas ou mais); tempo de vínculo (até 36 meses ou 37 meses ou mais); rendimento do trabalho (até $\mathrm{R} \$ 1.016,00$ ou $\mathrm{R} \$ 1.016,01$ ou mais); setor de trabalho (categorias binárias, contrastando a indústria, a construção, o comércio e os serviços em geral).

Para verificar a relevância desses atributos para a filiação de homens e mulheres, efetua-se uma análise de razões de chance, que resultam de regressões logarítmicas binomiais, focadas apenas em

\footnotetext{
Acerca da relevância de analisar quem são os perfis de trabalhadores que efetivamente respondem pela organização/mobilização dos sindicatos, ver Cardoso (1999); Rodrigues (1999).

2 A categorização "branca" incorpora as respostas "branca" e "amarela" da PNAD/IBGE. Já a categorização "negra" incorpora as respostas "preta", "parda" e "indígena".
} 
efeitos principais ${ }^{3}$. A figura 8 e as tabelas 2 e 3 (anexo) resumem o que foi encontrado com tais regressões, assim como o procedimento utilizado (seleções de variáveis, números de iterações, valores de quiquadrado, valores de Nagelkerke, valores de coeficientes, níveis de significância, índices de classificação, números de resíduos etc.). No ano de 2012, os atributos com maior importância para a filiação de homens e mulheres pareceram ser os ocupacionais ${ }^{4}$. As razões de chance de atributos como setor de trabalho, porte de estabelecimento, tempo de vínculo e rendimento de trabalho se mostraram superiores a todas as demais, referentes a atributos demográficos (figura 8$)^{5}$. Se fosse possível delinear um "tipo ideal", os homens e mulheres com mais chances de se filiarem aos sindicatos seriam aqueles que trabalhassem há mais tempo, em um grande estabelecimento, que pagasse maiores salários e que estivesse situado no setor industrial (especificamente no caso dos homens, no que concerne a este último atributo) ${ }^{6}$.

${ }^{3}$ É importante mencionar que, ao lidar com as razões de chance, contrastando os atributos dos trabalhadores e suas intenções de filiação aos sindicatos, não se afirma nada sobre relações de causalidade existentes. Ademais, é relevante destacar que, pelos motivos já expostos, a análise com as razões de chance é realizada a partir do mesmo recorte já utilizado: leva-se em conta apenas os trabalhadores assalariados e registrados, celetistas e estatutários, situados no Brasil urbano.

${ }^{4}$ Com a exceção da jornada de trabalho.

${ }^{5}$ Um exemplo de interpretação das razões de chance que constam da figura 9 é o seguinte: se as mulheres trabalham em estabelecimentos maiores (com 11 ocupados ou mais), elas têm uma chance $1,62 \mathrm{vez}$ maior de serem filiadas aos sindicatos do que aquelas que trabalham em estabelecimentos menores (com até 10 ocupados).

${ }^{6}$ Deve-se ter algum cuidado na análise das razões de chance vinculadas a setores de trabalho no caso das mulheres, pois os altos valores apresentados na figura 9 correspondem na verdade a valores inferiores à unidade, como pode ser visto na tabela 2. Sobre isso verificar a nota que acompanha a figura 9. 
Enfim, a filiação de homens e mulheres parece ser influenciada principalmente por atributos da esfera ocupacional. Isso faz sentido, pois a filiação dos trabalhadores é um aspecto próprio do âmbito sindical. E este último diz respeito a temas da esfera ocupacional (como mobilizações por melhores condições de trabalho, em defesa de remunerações mais elevadas, contra demissões de trabalhadores e assim por diante).

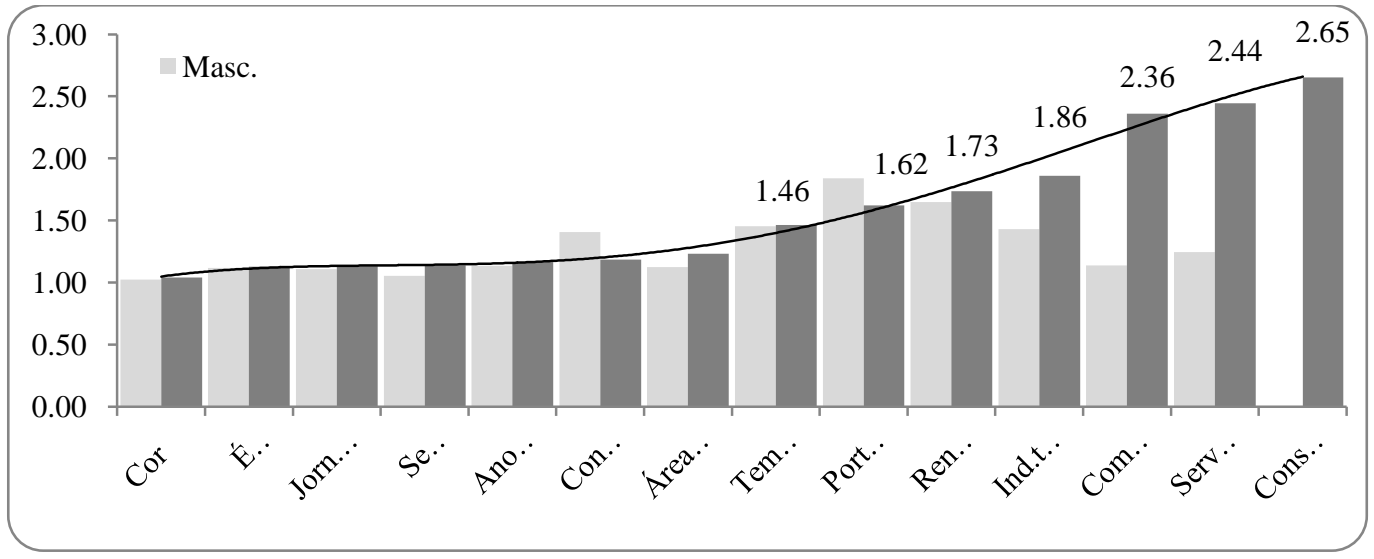

FIGURA 8. RAZÕES DE CHANCE. VARIÁVEL-RESPOSTA: SE É FILIADO OU Não. VARIÁVEIS-PREDITORAS: MÚLTIPLAS. ANO DE 2012

FONTE: MICRODADOS PNAD/IBGE. ELABORAÇÃO DOS AUTORES.

Nota: Trabalhadores de 16-65 anos, assalariados registrados, celetistas e estatutários, no Brasil urbano. Método utilizado: entrada forçada de variáveis, seleção única, não hierárquica, com até 20 interações, apenas com efeitos principais. Atributos do modelo do sexo feminino: Qui-quadrado (14) 451.655,26; $\mathrm{p}<=, 01$. Nagelkerke R2: ,058. Todos B com p <=,01. Correta classificação: 80,3\%. Percentual de resíduos estandartizados $>2=2,8 \%$. Atributos do modelo do sexo masculino: Qui-quadrado (14) $991.739,99 ; \mathrm{p}<=, 01$. Nagelkerke R2: ,078. Todos B com $\mathrm{p}<=, 01$, com exceção da variável 'Construção'. Correta classificação: 77,2\%. Percentual de resíduos estandartizados $>2=2,1 \%$. Valores do setor 'construção' não apresentados para o sexo masculino, pois não são estatisticamente significativos. Rótulos de valores 
apresentados: apenas os do sexo feminino. Ressalva: neste gráfico, se razão de chance $<1,00$, razão de chance $=1 /$ razão.

\section{Considerações finais}

A mobilização dos trabalhadores em organizações representativas, como os sindicatos, é uma questão relevante em meio aos estudos que compõem os campos da economia e da sociologia do trabalho. Mas, para compreender os sindicatos, é necessário entender as características e as dinâmicas do mercado de trabalho, para se obter uma visão geral da base social dessas instituições.

No Brasil dos anos 1990, o mercado de trabalho caracterizouse pelo desemprego e pela informalização da mão de obra, com consequências negativas como a pobreza e a desigualdade. Essa situação reverteu-se uma década depois, na primeira metade dos anos 2000, quando a taxa de desemprego teve uma queda significativa e quando ocorreu um aumento na formalização da mão de obra.

Ao longo desse período, houve variações significativas quando se diferencia a evolução dos indicadores por gênero, com uma tendência de diminuição das diferenças, embora os dados continuem desfavoráveis às mulheres. De fato, ao final dos anos 2000, o desemprego feminino ainda continuava superior ao masculino, sendo que o mesmo ocorria com a informalidade da ocupação. Ou seja, a inserção das mulheres no mercado de trabalho permanecia mais precária que a dos homens, ainda que ocorrido uma diminuição das diferenças. 
Isso pôde ser visto também no âmbito dos sindicatos. Nos anos 1990, essas instituições sofreram acentuadamente com a dinâmica do mercado de trabalho (desemprego, informalidade etc.). Já nos anos 2000, ao menos em certa medida, essa dinâmica se alterou, abrindo condições para que os sindicatos recuperassem seu protagonismo nesse mercado - o que foi registrado, de modo mais claro, no elevado número de greves e de negociações coletivas bem-sucedidas.

No que se refere à filiação de homens e mulheres, um aspecto importante dos anos 1990 e 2000 foi o grau de proximidade de ambos os gêneros aos sindicatos. As evidências empíricas apresentadas neste artigo mostraram que, em termos de taxa de filiação e também de perfil, ao final dos anos 2000, já quase não se registravam diferenças entre homens e mulheres. Em todas as regiões geográficas, assim como em todos os setores econômicos, ambos os gêneros se tornaram mais semelhantes no que concerne à proximidade com os sindicatos.

Isso representou algo bastante novo na história do sindicalismo brasileiro. Afinal de contas, os sindicatos sempre foram conhecidos como espaços masculinos, pouco permeáveis à presença feminina em sua organização e em sua mobilização. É verdade que, ao longo dos anos 1990 e 2000, eles passaram a incluir, em suas pautas, temas ligados aos interesses das mulheres em sua relação com o mundo do trabalho. Ademais, passaram também a integrar mais mulheres em sua estrutura de poder - conselhos, direções, presidências etc. Mas, de toda 
maneira, historicamente, os sindicatos foram conhecidos como espaços essencialmente masculinos.

Dessa forma, em que pesem as evidências mencionadas neste artigo, que mostram um grau de proximidade semelhante de homens e mulheres aos sindicatos no final dos anos 2000, é importante perguntar se isso se refletirá em espaços mais equilibrados entre os gêneros dentro dos sindicatos - equilibrados em termos de presença de homens e mulheres em suas estruturas, em suas pautas de mobilização e assim por diante. Tal questão, por si só, já abre um amplo leque para análises futuras.

\section{Referências}

ABRAMO, L. O resgate da dignidade: a greve de 1978 em São Bernardo. São Paulo: Universidade de São Paulo, 1986.

ANTUNES, R. Adeus ao trabalho? Ensaio sobre as metamorfoses e a centralidade do mundo do trabalho. São Paulo: Cortez, 1995.

BERTOLIN, P. T. M.; KAMADA, F. L. Ausentes ou invisíveis? Participação das mulheres nos sindicatos. Caderno Espaço Feminino, v. $25, \mathrm{n}^{\circ} 1,2012$.

CACCIAMALI, M. Globalização e processo de informalidade. Economia e Sociedade, v. 14, 2000.

CARDOSO, A. M. A década neoliberal e a crise dos sindicatos no Brasil. São Paulo: Boitempo Editorial, 2003. 
CARVALHAL, T. A questão de gênero sob a perspectiva sindical. Revista Pegada, v. 2, n 1, 2001.

CAMPOS, A. G. Dilemas do trabalho: sindicatos no Brasil hoje. In: KREIN, J.D.; CARDOSO JÚNIOR, J.C.; BIAVASCHI, M.B.; TEIXEIRA, M.O. (Orgs.). Regulação do trabalho e instituições públicas. 1a. ed. São Paulo: Fundação Perseu Abramo, 2013. v. 1. p. 87-122.

- Sindicatos no Brasil hoje: dilemas apresentados para a sindicalização. Boletim Mercado de Trabalho, nº 56, 2014.

CARDOSO, A. M. Sindicatos, trabalhadores e a coqueluche neoliberal: a era Vargas acabou? Rio de Janeiro: FGV, 1999.

. Os sindicatos no Brasil. Boletim Mercado de Trabalho, $\mathrm{n}^{\circ}$ 56, 2014.

- A década neoliberal e a crise dos sindicatos no Brasil. São Paulo: Boitempo Editorial, 2003.

. Para onde foram os sindicatos? In: KREIN, J.D.; CARDOSO JÚNIOR, J.C.; BIAVASCHI, M.B.; TEIXEIRA, M.O. (Orgs.). Regulação do trabalho e instituições públicas. São Paulo: Fundação Perseu Abramo, 2013.

GUIMARÃES, N. A. Os desafios da equidade: reestruturação e desigualdades de gênero e raça no Brasil. Cadernos Pagu, $\mathrm{n}^{\circ}$ 17/18, 2002.

IPEA. Um retrato de duas décadas do mercado de trabalho brasileiro utilizando a Pnad. Comunicados do IPEA, nº 160. Brasília: IPEA, 2013. LEMOS, M. R. Gênero, movimentos sociais e sindicatos trabalhistas: analisando representações femininas em espaços reivindicativos. Revista Sociais e Humanas, v. 24, nº 2, 2011. 
MENEGUELLO, R. PT: a formação de um partido. São Paulo: Paz e Terra, 1989.

NORONHA, E. G. A explosão das greves na década de 80. In: O sindicalismo brasileiro nos anos 80. São Paulo: Paz e Terra, 1991.

OLIVEIRA, F. Quanto melhor, melhor: o acordo das montadoras. Novos Estudos CEBRAP, São Paulo, nº 36, 1993.

RODRIGUES, I. J. O sindicalismo brasileiro: da confrontação à cooperação conflitiva. São Paulo em Perspectiva, São Paulo, v. 9, nº 3, 1995.

RODRIGUES, J. A. Sindicato e desenvolvimento no Brasil. São Paulo: Símbolo, 1979.

RODRIGUES, L. M. Partidos e sindicatos: escritos de sociologia política. São Paulo: Ática, 1989.

. CUT: os militantes e a ideologia. São Paulo: Paz e Terra, 1990.

SANDOVAL, S. Os trabalhadores param. São Paulo: Ática, 1994.

SILVA, S. P.; GONZALES, R. H. S. Evolução e descentralização territorial do emprego industrial no Brasil: algumas evidências para o debate atual. In: IPEA. Brasil em Desenvolvimento. Brasília: IPEA, 2013. v. 2. 
TABELA 2. REGRESSÃO LOGÍSTICA BINOMIAL. VARIÁVEL-RESPOSTA: SE É FILIADO OU NÃO.

VARIÁVEIS-PREDITORAS: MÚLTIPLAS. SEXO FEMININO. ANO DE 2012

\begin{tabular}{|c|c|c|c|c|c|}
\hline Atributos demográficos & B & EP & RC & $\begin{array}{l}\text { RC-Inf } \\
(95 \%)\end{array}$ & $\begin{array}{c}\text { RC-Sup } \\
(95 \%)\end{array}$ \\
\hline $\begin{array}{c}\text { Cor } \\
\text { (negra } \mathrm{x} \text { branca) }\end{array}$ & $-0,04$ & 0,00 & 0,96 & 0,96 & 0,96 \\
\hline $\begin{array}{l}\text { Condição na família } \\
\text { (outra x referência) }\end{array}$ & 0,17 & 0,00 & 1,18 & 1,18 & 1,19 \\
\hline $\begin{array}{c}\text { Se estuda } \\
\text { (não x sim) }\end{array}$ & $-0,13$ & 0,00 & 0,88 & 0,87 & 0,88 \\
\hline $\begin{array}{c}\text { Anos de estudo } \\
\text { (até } 11 \times 12 \mathrm{ou}+\text { anos) }\end{array}$ & 0,15 & 0,00 & 1,16 & 1,16 & 1,17 \\
\hline $\begin{array}{c}\text { Área de residência } \\
\text { (não metrop. x metrop.) }\end{array}$ & $-0,21$ & 0,00 & 0,81 & 0,81 & 0,81 \\
\hline $\begin{array}{l}\text { Se é migrante } \\
\text { (não x sim) }\end{array}$ & $-0,12$ & 0,00 & 0,89 & 0,88 & 0,89 \\
\hline Atributos ocupacionais & B & EP & RC & $\begin{array}{l}\text { RC-Inf } \\
(95 \%)\end{array}$ & $\begin{array}{c}\text { RC-Sup } \\
(95 \%)\end{array}$ \\
\hline $\begin{array}{c}\text { Porte do estabelec. } \\
\text { (até } 10 \times 11 \text { ou + ocupados) }\end{array}$ & 0,48 & 0,00 & 1,62 & 1,61 & 1,63 \\
\hline $\begin{array}{c}\text { Jornada de trabalho } \\
\text { (até } 40 \times 41 \mathrm{ou}+\text { horas) }\end{array}$ & 0,12 & 0,00 & 1,13 & 1,13 & 1,13 \\
\hline $\begin{array}{c}\text { Tempo de emprego } \\
\text { (até } 36 \text { x } 37 \text { ou + meses) }\end{array}$ & 0,38 & 0,00 & 1,46 & 1,46 & 1,47 \\
\hline $\begin{array}{c}\text { Rendimento mensal } \\
\text { (até } \mathrm{R} \$ 1.016,00 \times \mathrm{R} \$ 1.016,01 \\
\text { ou }+ \text { ) }\end{array}$ & 0,55 & 0,00 & 1,73 & 1,73 & 1,74 \\
\hline $\begin{array}{c}\text { Setor de trabalho } \\
\text { (outro x ind.transf.) }\end{array}$ & $-0,62$ & 0,03 & 0,54 & 0,51 & 0,57 \\
\hline $\begin{array}{c}\text { Setor de trabalho } \\
\text { (outro x construção) }\end{array}$ & $-0,98$ & 0,03 & 0,38 & 0,36 & 0,40 \\
\hline $\begin{array}{l}\text { Setor de trabalho } \\
\text { (outro x comércio) }\end{array}$ & $-0,86$ & 0,03 & 0,42 & 0,40 & 0,45 \\
\hline
\end{tabular}




\begin{tabular}{|c|c|c|c|c|c|}
\hline $\begin{array}{c}\text { Setor de trabalho } \\
\text { (outro x serviços) }\end{array}$ & $-0,89$ & 0,03 & 0,41 & 0,39 & 0,43 \\
\hline Constante & & & & & \\
\hline Bo & B & EP & RC & $\begin{array}{c}\text { RC-Inf } \\
\mathbf{( 9 5 \% )}\end{array}$ & $\begin{array}{c}\text { RC-Sup } \\
\mathbf{( 9 5 \% )}\end{array}$ \\
\hline
\end{tabular}

Legenda: B - Beta; EP - Erro Padrão; RC - Razão de Chance; RC-Inf. (95\%) Limite inferior do intervalo de confiança da razão de chance; RC-Sup (95\%) - Limite superior do intervalo de confiança da razão de chance. Grupo analisado: trabalhadores de 16-65 anos, do sexo feminino, assalariados registrados, celetistas e estatutários, no Brasil urbano. Método utilizado: entrada forçada de variáveis, seleção única, não hierárquica, com até 20 interações, apenas com efeitos principais. Atributos do modelo: Qui-quadrado (14) 451.655,26; $\mathrm{p}<=, 01$. Nagelkerke R2: ,058. Todos B com $\mathrm{p}<=, 01$. Correta classificação: $80,3 \%$. Percentual de resíduos estandartizados $>2=$ $2,8 \%$.

Fonte: Microdados PNAD/IBGE. Elaboração dos autores. 
TABELA 3. REGRESSÃO LOGÍSTICA BINOMIAL. VARIÁVEL-RESPOSTA: SE É FILIADO OU NÃO. VARIÁVEIS-PREDITORAS: MÚLTIPLAS. SEXO MASCULINO. ANO DE 2012

\begin{tabular}{|c|c|c|c|c|c|}
\hline Atributos demográficos & $\mathbf{B}$ & $\mathbf{E P}$ & $\mathbf{R C}$ & $\begin{array}{c}\text { RC-Inf } \\
\mathbf{( 9 5 \% )}\end{array}$ & $\begin{array}{c}\text { RC-Sup } \\
\mathbf{( 9 5 \% )}\end{array}$ \\
\hline $\begin{array}{c}\text { Cor } \\
\text { (negra x branca) }\end{array}$ & $-0,02$ & 0,00 & 0,98 & 0,97 & 0,98 \\
\hline $\begin{array}{c}\text { Condição na família } \\
\text { (outra x referência) }\end{array}$ & 0,34 & 0,00 & 1,41 & 1,40 & 1,41 \\
\hline $\begin{array}{c}\text { Se estuda } \\
\text { (não x sim) }\end{array}$ & 0,05 & 0,00 & 1,05 & 1,05 & 1,06 \\
\hline $\begin{array}{c}\text { Anos de estudo } \\
\text { (até 11 x 12 ou + anos) }\end{array}$ & 0,13 & 0,00 & 1,14 & 1,13 & 1,14 \\
\hline $\begin{array}{c}\text { Área de residência } \\
\text { (não metrop. x metrop.) }\end{array}$ & $-0,12$ & 0,00 & 0,89 & 0,89 & 0,89 \\
\hline $\begin{array}{c}\text { Se é migrante } \\
\text { (não x sim) }\end{array}$ & $-0,11$ & 0,00 & 0,90 & 0,89 & 0,90 \\
\hline $\begin{array}{c}\text { Atributos ocupacionais } \\
\text { Porte do estabelec. }\end{array}$ & $\mathbf{B}$ & $\mathbf{E P}$ & $\mathbf{R C}$ & $\begin{array}{c}\mathbf{R C}-\mathbf{I n f} \\
\mathbf{( 9 5 \% )}\end{array}$ & $\mathbf{R C - S u p}$ \\
$\mathbf{( 9 5 \% )}$
\end{tabular}




\begin{tabular}{|c|c|c|c|c|c|} 
& & & & & \\
\hline Constante & B & EP & RC & $\begin{array}{c}\text { RC-Inf } \\
(\mathbf{9 5 \% )}\end{array}$ & $\begin{array}{c}\text { RC-Sup } \\
(\mathbf{9 5 \%})\end{array}$ \\
\hline Bo & $-2,51$ & 0,01 & - & - & - \\
\hline
\end{tabular}

Legenda: B - Beta; EP - Erro Padrão; RC - Razão de Chance; RC-Inf. (95\%) Limite inferior do intervalo de confiança da razão de chance; RC-Sup (95\%) - Limite superior do intervalo de confiança da razão de chance. Grupo analisado: trabalhadores de 16-65 anos, do sexo masculino, assalariados registrados, celetistas e estatutários, no Brasil urbano. Método utilizado: entrada forçada de variáveis, seleção única, não hierárquica, com até 20 interações, apenas com efeitos principais. Atributos do modelo: Qui-quadrado (14) 991.739,99; p <= ,01. Nagelkerke R2: ,078. Todos B com $\mathrm{p}<=, 01$, com exceção de *. Correta classificação: 77,2\%. Percentual de resíduos estandartizados $>2=2,1 \%$.

Fonte: Microdados PNAD/IBGE. Elaboração dos autores. 